\title{
Determanation of Several Biochemical Parameters in Sera of Iraqi Patients with type 2 Diabetes
}

\author{
Layla O. Farhan*
}

Received 31, March, 2014

Accepted 15, June, 2014

(c) (i) ()

This work is licensed under a Creative Commons Attribution-NonCommercialNoDerivatives 4.0 International Licens

Abstract:

Diabetes mellitus, or simply diabetes, is a group of metabolic diseases in which a person has high blood sugar, either because the pancreas does not produce enough insulin, or because cells do not respond to the insulin that is produced. This high blood sugar produces the classical symptoms of polyuria (frequent urination), polydipsia (increased thirst), and polyphagia (increased hunger). The aim of the study is to measure several biochemical parameters in T2DM patients and the effect of these parameters in development the disease.

Laboratory investigations including Ceruloplasmin, fasting blood glucose (FBG) , malondialdehyde (MDA), serum protein, uric acid, and protein electrophoresis have been measured in patients with type 2 diabetes. Blood samples were obtained from the patients and matching group of healthy volunteer subjects were considered as control group who came to the AL-Yarmok hospital for health checkup.

There were significant differences in ceruloplasmin, FBG, malondialdehyde (MDA) , total protein, and uric acid,in the patients when compared to control group. There was a negative correlation between MDA $[\mu$ mol/l] with ceruloplasmin [mg/dl/] $(\mathrm{r}=0.43, \mathrm{p}<0.01)$, and positive correlation between $\mathrm{FBG}[\mathrm{mg} / \mathrm{dl} /]$ with uric acid $[\mathrm{mg} / \mathrm{dl} /](\mathrm{r}=0.43, \mathrm{p}<0.01)$, in patients group while no correlation was found among control subjects .

From these studies we can conclude that antioxidant defense is impaired in type 2 DM patients of increased oxidative stress.

Key words: Diabetes mellitus, antioxidant enzymes, FBG.

\section{Introduction:}

The term diabetes mellitus describes a metabolic disorder of multiple aetiology characterized by chronic hyperglycemia with disturbances of carbohydrate, fat and protein metabolism resulting from defects in insulin secretion, insulin action, or both [1]. The effects of diabetes mellitus include long- term damage, dysfunction and failure of various organs. Diabetes mellitus may present with characteristic symptoms such as thirst, polyuria, blurring of vision, and weight loss. In its most severe forms, ketoacidosis or a non- ketotic hyperosmolar state may develop and lead to stupor, coma and, in absence of effective treatment, death $[2,3]$.

When the diagnosis of diabetes is made, the clinician must feel confident that the diagnosis is fully established since the consequences for the individual are considerable and lifelong. The requirements for diagnostic confirmation for a person presenting with severe symptoms and gross hyperglycemia differ from those for the asymptomatic person with blood glucose values found to be just

*Department of Chemistry, College of Science for Women, University of Baghdad, Baghdad, Iraq. 
above the diagnostic cut-off value. Severe hyperglycemia detected under conditions of acute infective, traumatic, circulatory or other stress may be transitory and should not in itself be regarded as diagnostic of diabetes [4]. The diagnosis of diabetes in an asymptomatic subject should never be made on the basis of a single abnormal blood glucose value. For the asymptomatic person, at least one additional plasma/blood glucose test result with a value in the diabetic range is essential, either fasting, from a random (casual) sample, or from the oral glucose tolerance test (OGTT) [ 5].

Oxidative stress is defined as oxygen radical mediated damage to biological material (proteins, lipids, carbohydrates, and DNA) caused by either increased generation and build up of the oxygen radicals (superoxide radical, hydrogen peroxide, and the hydroxyl radical), or due to the diminished removal or inadequate protection against these ubiquitously present oxygen radicals. During evolution of aerobic life, powerful antioxidant enzymes and radical scavengers have developed to remove or scavenge these oxygen radicals in order to protect cell organelles and membranes [6]. For some time, it has been recognized that serum uric acid (UA) is positively associated with serum glucose levels in healthy subjects [7 ]. Recent studies have demonstrated that UA levels are higher in subjects with pre diabetes and early Type 2 diabetes then in healthy controls [8 ] Furthermore, an elevated serum UA level was found to increase chances for developing Type $\mathrm{W}$ diabetes in individuals with impaired glucose tolerance [9 $]$. Hyperuricemia has been also added to the set of metabolic abnormalities associated with insulin resistance and/or hyperinsulinemia in metabolic syndrome [10].

Ceruloplasmin (EC 1.16.3.1) is an acute phase reactant, has ferro-O2 oxidoreductase (pro-oxidant) activity directed towards ferrous ion stimulated lipid peroxidation and formation of hydroxyl radical in Fenton reaction [11]. Ceruloplasmin (Cp) is a circulating blue multicopper oxidase that contains $>95 \%$ of copper in the plasma. $\mathrm{Cp}$ is synthesized mainly in the liver as a single chain polypeptide, and after the incorporation of six atoms of copper early in the biosynthetic pathway, it is secreted into the plasma as an ai-glycoprotein [12]. Although its precise biological roles are unknown, it may be related to angiogenesis [13], copper transport [14], iron metabolism , and antioxidant defense [15].

Malondialdehyde (MDA) has been widely used as an indicator of oxidative stress. and lipid peroxidation [16] Diabetes is commonly accompanied by the extended production of reactive oxygen species (ROS) and/or impaired antioxidant defense mechanisms. Moreover, lipid peroxidation often occurs in response to enhanced oxidative stress, and malondialdehyde (MDA) is one of low-molecular weight end products formed via decomposition of certain primary and secondary products of cell membrane injury due to lipid peroxidation [17].

Uric acid is the final breakdown product of dietary or endogenous purines and is generated by xanthine dehydrogenase (xanthine oxidase) primarily in the liver and intestine. Exogenous purines also represent an important source of uric acid, and approximately $50 \%$ of RNA purines and $25 \%$ of DNA purines are absorbed in the intestine and subsequently excreted in urine. In adult humans, the uric acid pool is around 
$1.2 \mathrm{~g}$ and undergoes rapid turnover, with two thirds of the uric acid pool excreted in urine. The kidneys handle ureters in multiple processes, including glomerualr filtration and reabsorption, secretion, and post secretory absorption in the proximal convoluted tubules. The uprate handling by kidneys could be affected by various factors like extra cellular volume status, urine flow rate, urine $\mathrm{pH}$, urate load, and hormones [18].

Electrophoresis is a technique for separation of different charged particles. It is based on movement of charged particles through a solution when subjected to an electrical field[19]. Separation of serum protein fractions is very important for the diagnosis of different diseases like paraproteinaemias,

haemoglobinopathies, immune deficiency and genetic abnormalities [20].

The aim of study is to measure FBG, ceruloplasmin, MDA, uric acid and total protein in T2DM patients and effect of these parameters in development the disease.

\section{Materials and Methods:}

Five $\mathrm{ml}$ have been collected from each subject by vein puncture, centrifuged at $3000 \mathrm{rpm}$ for $5 \mathrm{~min}$ after allowing the blood to clot at room temperature.

The study group consisted of total 60 subject which included non -diabetic healthy control subjects $(n=30)$ and diabetic patient $(n=30)$. The patient has been diagnosed by specialist doctors in AL-Yarmok hospital (National Diabetes Center). All patients were questioned some information like history taking, thorough clinical examination. The MDA was measured by Thiobarbituric acid reactive substances assay (TBRAS) method, The principle of the method was based on the spectrophotometric measurement of the colour developed during the reaction of thiobarbituric acid with MDA. The concentration of thiobarbituric acid reactive substances was calculated by the absorbance coefficient of malondialdehyde thiobarbituric acid complex [21]. Serum ceruloplasmin was estimated by kinetic method [22 ] . Fasting serum glucose, uric acid were measured by enzymatic method supplied by Randox kit . protein electrophoresis have been done by cellulose acetate paper. Statistical analyses of this study were performed using SPSS version 15.0 for Windows (Statistical Package for Social Science, Inc., Chicago, IL, USA). Descriptive analysis was used to show the mean and standard deviation of variables. The significance of difference between mean values was estimated by Student T-Test. The probability $P<0.05=$ significant,$P>$ $0.05=$ non-significant. Correlation analysis was used to test the linear relationship between parameters. ANOVA test was used to show the differences between variables of differentiated groups.

\section{Results and Discussion:}

The present study found significant increase in levels of FPG, MDA and uric acid $(\mathrm{P}<0.01)$, and decrease in ceruloplasmin $(P<0.001)$ in type $2 \mathrm{DM}$ patients compared to healthy controls as shown in table 1 . 
Table 1: The mean and standard deviation of Age, FBG, Ceruloplasmin MDA, and Uric acid, in patients group and control group.

\begin{tabular}{|c|c|c|c|}
\hline Characteristic & $\begin{array}{c}\text { Patients } \\
{[\text { mean } \pm \mathbf{S}]} \\
{[\mathbf{n}=\mathbf{3 0}]}\end{array}$ & $\begin{array}{c}\text { control } \\
{[\text { mean } \pm \text { SD }]} \\
{[n=20]}\end{array}$ & $p$ Vale \\
\hline Age year & $53.06 \pm 8.97$ & $50 \pm 8.5$ & N.S \\
\hline FBG $[\mathrm{mg} / \mathrm{dl}]$ & $\begin{array}{l}163.06 \\
\pm 66.66\end{array}$ & $100 \pm 6.99$ & $<0.001$ \\
\hline Ceruloplasmin[mg/dl] & $14.03 \pm 6.008$ & 35.23 & $<0.001$ \\
\hline MDA $[\mu \mathrm{mol} / \mathrm{L}]$ & $2.69 \pm 1.37$ & $1.43 \pm 0.22$ & $<0.001$ \\
\hline Uric acid[mg/dl] & $4.12 \pm 1.18$ & $3.82 \pm 0.59$ & $<0.01$ \\
\hline Total protein[mg/dl] & $5.8 \pm 0.86$ & $7.0 \pm 0.70$ & $<0.05$ \\
\hline
\end{tabular}

In this study, we reported an increase of MDA levels in all type 2 diabetic patients, This finding can be attributed to the mechanisms of oxidative stress provoked mainly by chronic hyperglycemia, which is a characteristic of diabetes, regardless of the presence of disease complications, such as nephropathy, retinopathy, neuropathy or history of macro vascular complications, such as acute myocardial infarction, stroke, and peripheral vascular disease, since patients with these complications were excluded from the study population. It is possible to demonstrate that lipid peroxidation and hyperglycemia are associated with the disease progression and the development of chronic complications based on the correlations between serum levels of MDA and fasting glucose [23].

Ceruloplasmin serves as a ferroxidase that converts toxic ferrous iron to nontoxic ferric ion, which binds to transferrin [24]. It acts as an antioxidant by removing the free ferrous ion which acts as a major producer of oxidants (superoxide and hydroxyl radicals) [25]. In addition to this, ceruloplasmin also acts as an antioxidant by catalyzing the destruction of oxygen radicals, and can bind to and inhibit neutrophil myeloperoxidase oxidant activity [26].

Hyperglycemia and enhanced ROS lead to an increase of vascular endothelial growth factor, cytokines, and other inflammatory mediators, which, in turn, cause damage to the glomerular endothelial glycol calix leading to the onset of urinary albumin excretion in diabetes $[27,28]$. Possible increase in ceruloplasmin mediated generation of ROS leading to increase consumption of available antioxidants in the body. It appears that increased oxidative stress in presence of hyperglycemia may lead to increased availability of transition metals like MDA released from its storage site[29].

Recognition of high serum uric acid as a risk factor for diabetes has been a matter of debate for a few decades, since hyperuricemia has been presumed to be a consequence of insulin resistance rather than its precursor. However, recent findings suggest that uric acid could be related to the development of diabetes. Serum uric acid has been shown to be associated with oxidative stress, and production of tumor necrosis factor- $\alpha$ [30] which are both related to the development of diabetes. In addition, a recent study in rats showed that fructose-induced hyperuricemia plays a pathogenic role in the metabolic syndrome [31]. Recent studies have introduced serum uric acid as a potential risk factor for hypertension [32] stroke [33] and cardiovascular diseases [34].

In this study, a significantly negative association was observed between ceruloplasmin $[\mathrm{mg} / \mathrm{dl}]$ with $\operatorname{MDA}[\mu \mathrm{mol} / \mathrm{L}](\mathrm{R}=0.43, \mathrm{p}<0.01)$, and positive association was observed between FBG with uric acid[mg/dl] $[\mathrm{mg} / \mathrm{dl}](\mathrm{R}=0.43, \mathrm{p}<0.01)$, in type 2 $\mathrm{DM}$ patients while there was no significant correlation was observe in the controls as shown in figure 1. 

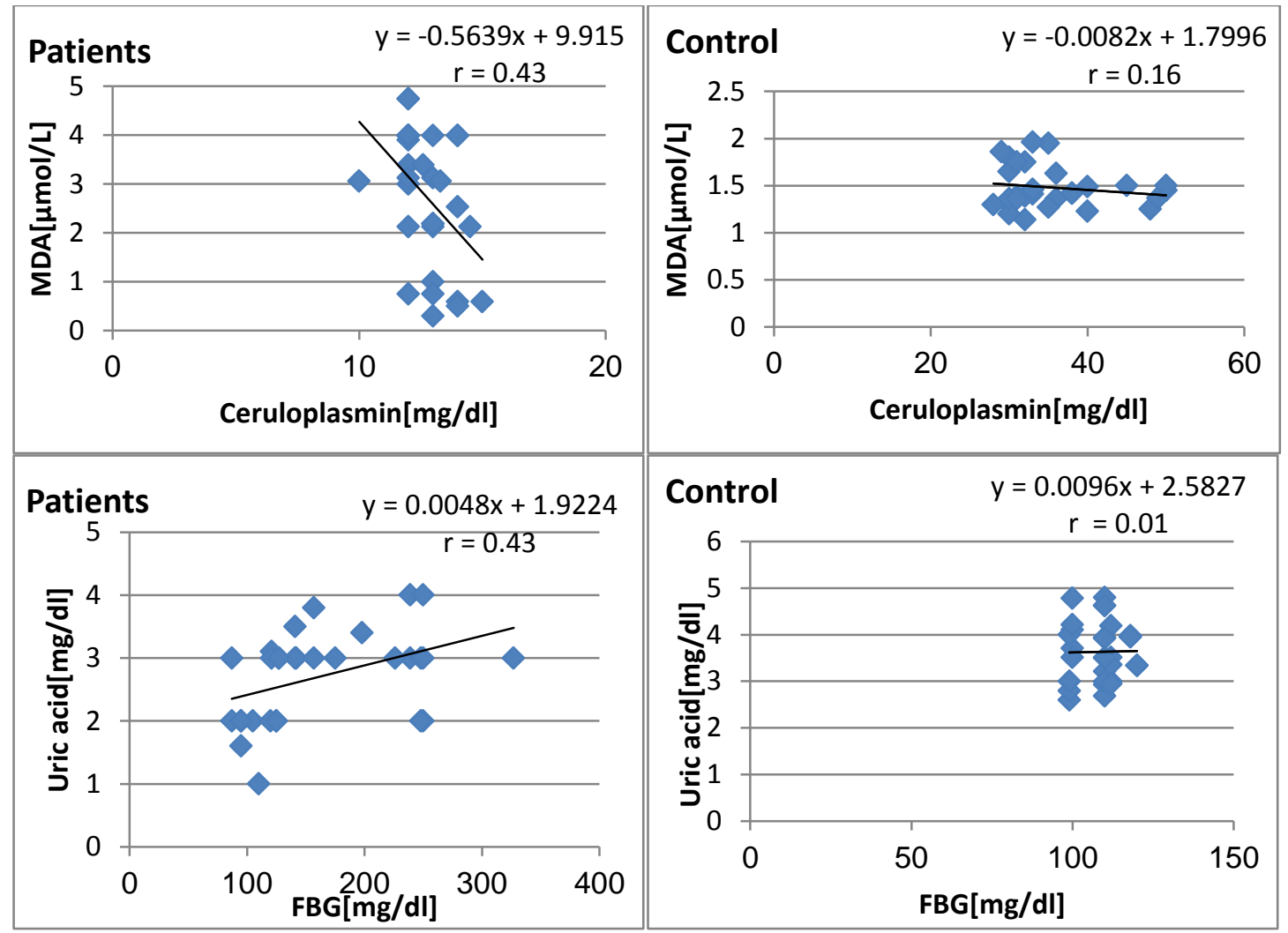

Fig 1: Correlation between Ceruloplasmin with MDA and FBG with Uric acid in type $2 \mathrm{DM}$ patients and control.

Cellulose acetate electrophoresis was carried out on sera samples of control and patients groups to detect the differences in total proteins present in the studied samples (to differentiate between protein patterns). After electrophoresis, the separated serum protein bands were detected using ponceau S-stain. Figure 2 shows the results of electrophoretic profile of proteins present in crude sera of all studied groups.

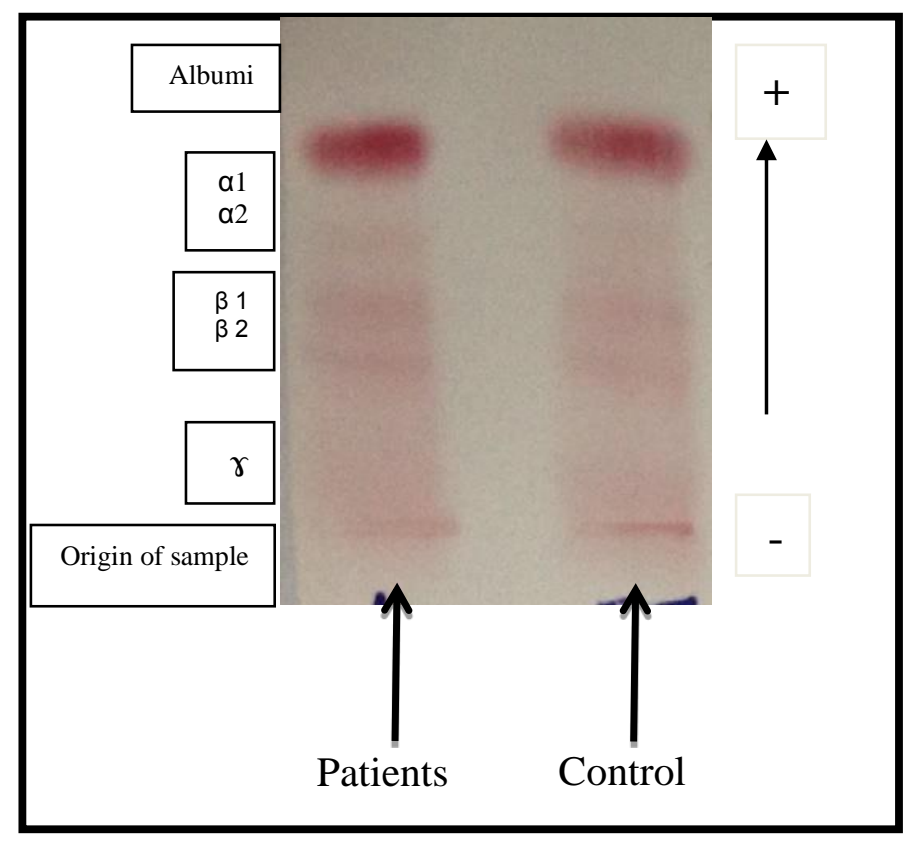

Fig 2 : Electrogram of Proteins Profile Samples. 
The electrogram of all studied group indicates that the sera was separated into distinct bands: albumin, $\alpha 1-$ and $\alpha 2$-globulins, $\beta 1$-and $\beta 2$ globulins and $\gamma$-globulins and that the albumin had the maximum and gammaglobulin had the minimum mobility in the electrical field, that is due to the fact that albumin is a protein with the most negative charges and it contains the most acidic amino acids with COO- groups $[35,36]$.

Decreased concentration of serum total protein indicates significant pathology either in the production of albumin by the liver or its leakage through a damaged surface (glomerular disease, gastrointestinal loss, or thermal injury) . In Western countries, a decrease in the production of albumin most commonly reflects severe liver injury. Because of the large reserve capacity of the liver, hypoalbuminemia resulting from liver damage occurs after most of the hepatocytes have been damaged or destroyed [37].

A decreased concentration of serum albumin may also result from excessive loss through injury to the kidneys, gastrointestinal tract, thermal injury to the skin or severe eczema, and in hypercatabolic states. When renal damage is severe enough to allow albumin to pass in large amounts into the urine, there is a corresponding loss of other serum proteins including g-globulins [38]. Some of the largest serum proteins, such as a2macroglobulin with a molecular mass of $720 \mathrm{kDa}$, remain in the serum and are synthesized at an increased rate. These probably constitute the body's attempt to

stabilize oncotic pressure[39].

\section{Conclusions:}

The present study indicates a possible decrease in ceruloplasmin mediated generation of ROS leading to increased consumption of available antioxidants in the body. It appears that increased oxidative stress in presence of hyperglycemia may lead to increased availability of transition metals like MDA released from its storage site .

\section{References:}

1- Sato K K; Hayashi T; Harita N; Yoneda T; Nakamura Y; Endo G and Kambe H. 2009. Combined measurement of fasting plasma glucose and A1C is effective for the prediction of type 2 diabetes: the Kansai Healthcare Study. Diabetes Care 32:644-646.

2- Pradhan AD; Rifai N; Buring JE and Ridker PM. 2007. Hemoglobin A1c predicts diabetes but not cardiovascular disease in nondiabetic women. Am J Med;120: 720-727.

3- Landon MB; Spong CY; Thom E; Carpenter MW; Ramin SM; Casey B; Wapner RJ; VarnerMW; Rouse DJ; Thorp JM, Jr.; Sciscione A; Catalano P; Harper M; Saade G; Lain K Y; Sorokin Y; Peaceman AM; Tolosa JE and Anderson GB. 2009. A multicenter, randomized trial of treatment for mild gestational diabetes. N Engl J Med ;361:1339-1348.

4- Thoolen B; De Ridder D; Bensing J; Maas C; Griffin S; Gorter $\mathrm{K}$ and Retten G . 2007. Effectiveness of a self-management intervention in patients with screen-detected type 2 diabetes. Diabetes Care; 30(11) :2832-7.

5- Mc Cance D R; Hanson R L; Charles M A; Jacobsson LTH; Pettitt D J; Bennett PH and Knowler C. 1994. Comparison of tests for glycated haemoglobin and fasting and two hour plasma glucose concentrations as diagnostic methods for diabetes. BMJ; 308: 1323-28. 
6- Olanow CW. 1993. A radical hypothesis for neurodegeneration. Trends Neurosci;16:439-44.

7- Coyle JT, 1993. Puttfarcken P. Oxidative stress, glutamate and neurodegenerative disorders. Science ;262:689-95.

8- Zargar A H; Shah N A; Masoodi S R; Laway B A; Dar F A, Khan A R; Sofi F A; Wani A I . 2002. Copper, zinc and magnesium levels in type-1 diabetes mellitus. Saudi Med J 23:539-542.

9- Brownlee M. 2001. Biochemistry and molecular cell biology of diabetic complications. Nature ;414 :813-20.

10- Pari L, Latha M. 2002. Effect of Cassia auriculata flowers on blood sugar levels, serum and tissue lipids in streptozotocin diabetic rats. Singapore Med J; 43:617-21.

11-Basu, AK. and Marnett ,L.; 1983. Unequivocal demonstration that malondialdehyde is a mutagen.; Carcinogenesis; 4(3): 331-333.

12- Raju K S; Alessandri G; Ziche M and Gullino PM: 1982 Ceruloplasmin, copper ions, and angiogenesis. ] Natl Cancer Inst 69:1183-1188.

13- Ryden L; Eaker D. 1983. Identification of thiol groups in human ceruloplasmin. Eur J Biochem 132:241-247.

14- Frieden E. 1986. Perspectives on copper biochemistry. Clin Physiol Biochem 4:11-19.

15- Goldstein I M; Kaplan H B; Edelson HS; and Weissmann G. 1979. Ceruloplasmin, a scavenger of superoxide anion radicals. J Biol Chem 254:4040-4045.

16- Palanduz S; Ademoglu E; Gokkusu $\mathrm{C}$ and Tamer S. 2001. Plasma antioxidants and type 2 diabetes mellitus. Res Commun Mol Pathol Pharmacol; 109:309-18.

17- Davì G; Falco A; and Patrono C. 2005. Lipid peroxidation in diabetes mellitus. Antioxid Redox Signal; 7:256-68.

18- S .Pati ; P. Sahu; and P . Mohapatra 2004. The role of uric acid in cardiovascuiar disease and its clinical implications ovissa medical biochemistry " $\mathrm{V}, 1$.

19- Gowenlock AH; McMurray JR; Mc Lauchlan D M; eds. 1987. Separative procedures, electrophoresis. In: Varley's Practical clinical biochemistry. Heinman medical books, London.; 69-81.

20- Whicher J T; Calvin J; Riches $\mathrm{P}$ and Warren C, 1987.The laboratory investigation of paraproteinaemia. Ann Clin Biochem; 24 : 119-32.

21- Stocks, J and Dormandy, T. 1971. The autoxidation of human red cell. Lipid induced by hydrogen peroxide. Br. J. Haematol. 20(1): 95-111.

22-Somani B L and Ambade V. 2005. Novel composition for kinetic assay of ceruloplasmin. Clin Chem; 51: Suppl A90.

23. Incerti J; Zelmanovitz T; Camargo J L; Gross J L; de Azevedo M J. 2005. Evaluation of tests for microalbuminuria screening in patients with diabetes. Nephrol Dial Transplant;20:2402-7.

24- Kruszewski M: Labile iron pool: 2003. The main determinant of cellular response to oxidative stress. Mutat Res.; 531: 81 -92.

25-Patel B N; Dunn R J; Jeong S Y; Zhu Q; Julien J P and David S. 2002. Ceruloplasmin regulates iron levels in the CNS and prevents free radical injury. J Neurosci.; 22: 6578 $-6586$.

26-Park Y S; Suzuki K; Mumby S; Taniguchi $\mathrm{N}$ and Gutteridge JM. 2000. Antioxidant binding of caeruloplasmin to myeloperoxidase: Myeloperoxidase is inhibited, but oxidase, peroxidase and immunoreactive properties of 
caeruloplasmin remain intact. Free Radic Res.; 33: 261 -265.

27. Satchell SC and Tooke JE. 2008 .What is the mechanism of microalbuminuria in diabetes: a role for the glomerular endothelium? Diabetologia ;51:714-25

28. Piarulli F; Sartore G; Ceriello A; et al. 2009. Relationship between glyco-oxidation, antioxidant status and microalbuminuria in type 2 diabetic patients. Diabetologia; 52:1419-25.

29-Mc Dermott B M; Flatt PR; and Strain JJ. 1994 . Effects of copper deficiency and experimental diabetes on tissue antioxidant enzyme levels in rats. Ann Nutr Metab; 38(5): 263-9.

30-Butler R; Morris A D; Belch J J; Hill A and Struthers AD. 2000. Allopurinol normalizes endothelial dysfunction in type 2 diabetics with mild hypertension. Hypertension 35: 746-751.

31-Nakagawa T; Hu H; Zharikov S; Tuttle KR; Short RA; Glushakova O; Ouyang X; Feig DI; Block ER; Herrera-Acosta J, Patel JM and Johnson RJ. 2006. A causal role for uric acid in fructose-induced metabolic syndrome. Am J Physiol Renal Physiol 290: F625-F631.

32-Johnson R J; Feig D I; HerreraAcosta J and Kang DH. 2005. Resurrection of uric acid as a causal risk factor in essential hypertension. Hypertension 45: 18-20.

33-Baker J F; Krishnan E; Chen L and Schumacher HR. 2005. Serum uric acid and cardiovascular disease: recent developments, and where do they leave us? Am J Med 118: 816826.

34 -Bos M J; Koudstaal P J; Hofman A; Witteman JCM and Breteler MMB. 2006. Uric acid is a risk factor for myocardial infarction and stroke: the Rotterdam Study. Stroke 37: 1503-1507.

35-Goljan E and Sloka KI. 2008. Laboratory testing in clinical medicine. 1st edn. Mosby Elsevier Inc Publications, USA. pp. 283-6.

36- Attaur RK, Moeen H S and Kiran I . 2006 . Effect of hypoproteinemia on treatment outcome in children with acute lymphoblastic leukemia, J Ayub Medical College 18(2):5356.

37-Yeung CY; Fung YS; and Sun DX. 2001. Capillary electrophoresis for the determination of albumin binding capacity and free bilirubin in jaundiced neonates. Semin Perinatol ;25:50-54.

38-Fung YS; Sun DX; and Yeung CY. 2000.Capillary electrophoresis for determination of free and albuminbound bilirubin and the investigation of drug interaction with bilirubin-bound albumin. Electrophoresis;21:403-410.

39- Levinson SS. 2000.Urine protein electrophoresis and immunofixation electrophoresis supplement one another in characterizing proteinuria. Ann Clin Lab Sci ;30:79-84. 


\section{تقدير عدة عوامل كيميائية حياتية في امصال المرضى العراقيين المصابين بداء السكري \\ ليلى عثمان فرحان}

قسم الكيمياء ،كلية العلوم للبنات ،جامعة بغداد

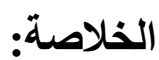

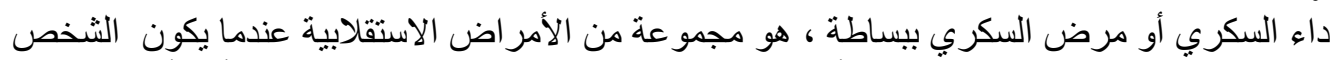

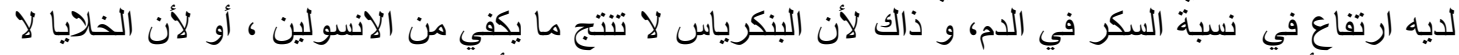

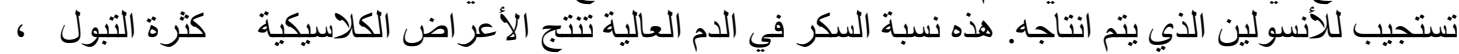

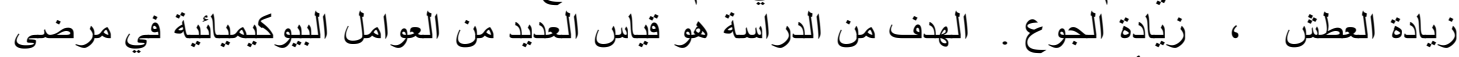

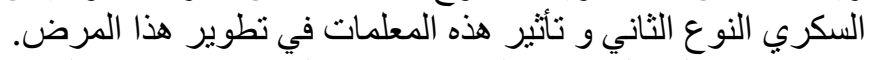

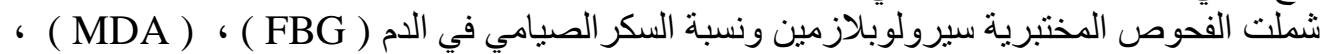

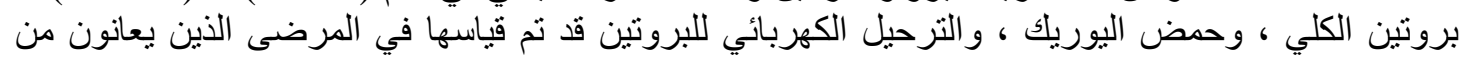

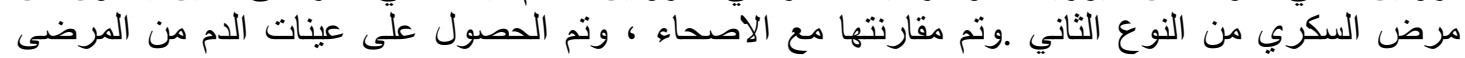

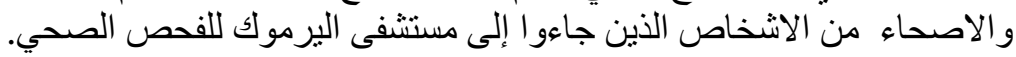

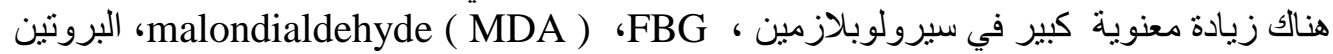

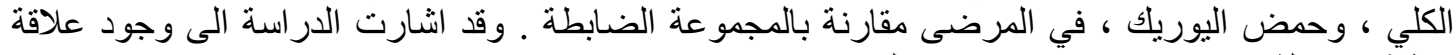

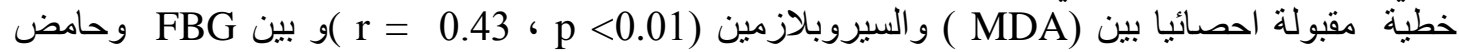

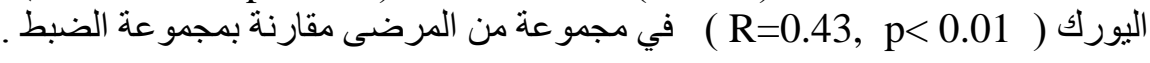
الكلمات المفتاحية: داء السكري، الانزيمات المضادة للأكسدة، سكر الدم الصيامي. 